\title{
Pembelajaran Berbasis Riset untuk Meningkatkan Kemampuan Multipel Representasi Mahasiswa dalam Memahami Soal HOTS
}

\author{
Apriliana Drastisianti ${ }^{1}$, Dante Alighiri ${ }^{2}$ \\ Jurusan Pendidikan Kimia, FST, Universitas Islam Negeri Walisongo ${ }^{1}$ \\ Jurusan Kimia, FMIPA, Universitas Negeri Semarang ${ }^{2}$ \\ E-mail: apriliana.drastisianti@walisongo.ac.id
}

\begin{abstract}
Abstrak
Mahasiswa pendidikan kimia sebagai calon guru kimia harus menguasai kompetensi guru salah satunya kompetensi pedagogik. Upaya untuk membekali mahasiswa pendidikan kimia agar memiliki kompetensi tersebut salah satunya dengan membuat soal HOTS (Higher Order Thinking Skills) dalam proses pembelajaran. Penelitian ini merupakan penelitian pengembangan dan bertujuan untuk mengetahui kemampuan mahasiswa pendidikan kimia dalam membuat soal HOTS berbasis multipel representasi. Penelitian dilakukan dengan menggunakan prosedur pengembangan Borg \& Gall yang berupa 10 tahap, tetapi dibatasi hanya sampai tahap 7. Pengambilan data dilakukan dengan lembar angket, uji coba soal, dan wawancara. Soal-soal yang dibuat oleh mahasiswa dikategorikan berdasarkan ranah kognitif taksonomi Bloom dan diperoleh 40 soal dengan rincian soal ranah C1 30\%, C2 17,50\%, C3 15\%, C4 $22,50 \%$, C5 10\%, dan C6 5\%. Soal dengan kategori HOTS sebanyak 15 soal (37,50\%). Soal HOTS tersebut dianalisis lebih lanjut dan diperoleh reliabilitas sebesar 0,78 (tinggi) dan 11 soal memenuhi kriteria sehingga dapat digunakan. Kemampuan multipel representasi mahasiswa dalam menyusun soal HOTS mengalami peningkatan.
\end{abstract}

Kata kunci: HOTS, kompetensi pedagogik, multipel representasi

\section{Research-Based Learning to Increase Student Representation Multiple Ability in Understanding HOTS Questions}

\author{
Apriliana Drastisianti ${ }^{1}$, Dante Alighiri ${ }^{2}$ \\ Jurusan Pendidikan Kimia, FST, Universitas Islam Negeri Walisongo ${ }^{1}$ \\ Jurusan Kimia, FMIPA, Universitas Negeri Semarang ${ }^{2}$ \\ E-mail: apriliana.drastisianti@walisongo.ac.id
}

\begin{abstract}
Chemistry education students as chemistry teacher candidates must master teacher competencies, one of which is pedagogical competence. One of the efforts to equip chemistry education students to have these competencies is by making HOTS (Higher Order Thinking Skills) questions in the learning process. This research is a development research and aims to determine the ability of chemistry education students in making HOTS questions based on multiple representations. The research was conducted using the Borg \& Gall development procedure in the form of 10 stages, but it was limited to stage 7. Data was collected using a questionnaire sheet, test questions, and interviews. The questions made by students were categorized based on the cognitive domain of Bloom's taxonomy and obtained 40 questions with details of questions in the domains of C1 30\%, C2 17.50\%, C3 15\%, C4 22.50\%, C5 10\%, and $\mathrm{C} 65 \%$. There are 15 questions in the HOTS category (37.50\%). The HOTS question was analyzed further and obtained reliability of 0.78 (high) and 11 questions met the criteria so that it could be used. The ability of multiple representations in composing HOTS questions has increased.
\end{abstract}

Keywords: HOTS, pedagogic competence, multiple representations 


\section{PENDAHULUAN}

Pembelajaran abad 21 menekankan kemampuan berpikir kritis dan kreatif, menghubungkan dengan dunia nyata, menguasai teknologi, keterampilan komunikasi dan kolaborasi (Afriyanti et al., 2018). Keterampilan tersebut diperlukan oleh peserta didik untuk menghadapi tantangan global. Mahasiswa pendidikan kimia sebagai calon guru kimia harus menguasai keterampilan abad 21. Keterampilan tersebut perlu dikuasai agar mahasiswa berhasil menghadapi tantangan dan permasalahan kehidupan dan karir (Redhana, 2019). Mahasiswa pendidikan kimia juga perlu menguasai kompetensi pedagogik yang merupakan salah satu kompetensi yang harus dimiliki oleh guru. Kompetensi pedagogik merupakan kemampuan mengelola pembelajaran yang meliputi pemahaman peserta didik, perancangan dan pelaksanaan pembelajaran, evaluasi hasil belajar dan pengembangan peserta didik untuk mengaktualisasikan potensi yang dimiliki. Penguasaan keterampilan abad 21 akan mendukung tercapainya kompetensi pedagogik. Salah satu kompetensi pedagogik adalah kemampuan guru dalam mengevaluasi hasil belajar peserta didik menggunakan instrumen soal yang dibuat sesuai dengan indikator. Pemberian umpan balik dan evaluasi dalam proses pembelajaran sangat penting karena untuk mengetahui sejauh mana tujuan pembelajaran tercapai dan merupakan salah satu cara untuk mengembangkan keterampilan berpikir mahasiswa (Limbach \& Waugh, 2010). Evaluasi pembelajaran dapat dilakukan selama proses pembelajaran berlangsung dengan observasi saat kegiatan belajar mengajar dan evaluasi setelah proses pembelajaran selesai (Yusuf \& Widyaningsih, 2018).

Instrumen yang digunakan sebagai alat evaluasi pembelajaran dapat berupa soal-soal dan calon guru kimia harus mampu menyusun soal sebagai alat evaluasi hasil belajar. Pembuatan soal evaluasi seringkali menjadi hal yang disepelekan. Soal evaluasi sangat berpengaruh untuk mengukur ketercapaian belajar peserta didik bahkan keberhasilan seorang pendidik dalam menyampaikan materi. Soal-soal evaluasi tersebut diharapkan mampu melatih dan membangun kemampuan peserta didik untuk menyampaikan argumen dan berpikir pada level kognitif yang lebih tinggi (Kusuma et al., 2017). Peserta didik harus mampu menghubungkan atau membandingkan antara situasi fakta, ide, atau dalam ketercapaian belajar siswa kejadian dengan fakta, ide, atau kejadian yang lain. Beberapa guru kimia belum pernah membuat soal HOTS baik dalam 
ulangan harian maupun ujian semester dan sebagian guru kimia belum pernah mendapatkan pelatihan penyusunan soal HOTS (Khaldun et al., 2019). Soal-soal yang digunakan masih menggunakan tiga level terendah yaitu C1, C2, dan C3. Soal Higher Order Thinking Skills (HOTS) dapat meningkatkan kemampuan berpikir, kreativitas, dan kemandirian belajar (Voogt \& Pareja Roblin, 2010). Soal HOTS dikembangkan dari berbagai konsep dan metode kognitif. Keterampilan berpikir tingkat tinggi dimasukkan dalam kurikulum yang merupakan pedoman penting pendidikan dimana peserta didik dituntut menjadi kreatif, kritis, dan inovatif. Peserta didik tidak hanya dituntut memiliki kemampuan mengingat, memahami, dan mengaplikasikan, tetapi juga dituntut untuk cakap dalam menganalisis, evaluasi, dan mencipta sehingga mampu memecahkan masalah yang tidak familiar maupun yang membutuhkkan solusi yang belum pernah dilakukan sebelumnya (Widana, 2017). Kemampuan berpikir tingkat tinggi mampu melatih untuk berpikir secara luas dalam menemukan tantangan baru (Heong et al., 2011).

Mahasiswa pendidikan kimia sebagai calon guru kimia harus dapat mengajarkan keterampilan berpikir tingkat tinggi sejak dini sehingga peserta didik mampu membangun argumen yang tepat untuk membuat keputusan. Keterampilan berpikir tingkat tinggi mampu melatih peserta didik untuk mengenali lingkungan sekitar, menganalisis bacaan dengan cermat, membaca grafik atau tabel, menjadi pribadi yang berkualitas. Calon guru kimia harus mampu menyusun soal evaluasi HOTS. Pedoman dalam menulis soal HOTS yaitu materi yang akan ditanyakan diukur dengan perilaku sesuai ranah kognitif Bloom yaitu menganalisis, mengevaluasi, dan mencipta. Butir soal harus memiliki stimulus yang dapat berbentuk sumber atau bahan bacaan sebagai informasi yang dapat berupa teks bacaan, paragraf, gambar, grafik, tabel, rumus, dan suatu kasus. Penggunaan stimulus dalam soal HOTS juga berkaitan dengan kemampuan representasi makroskopik, submikroskopik, dan simbolik atau yang dikenal dengan multipel representasi. Soal HOTS yang disusun menerapkan ketiga representasi kimia tersebut sehingga melatih mahasiswa sebagai calon guru kimia untuk menyusun soal HOTS berbasis multipel representasi.

Multipel representasi diperlukan selama proses pembelajaran dan setelah pembelajaran yaitu dalam soal-soal evaluasi yang menuntut berpikir tingkat tinggi sehingga meningkatkan hasil belajar (Widarti et al., 2020). Pembelajaran kimia yang selama ini berlangsung belum mampu 
memunculkan kemampuan representasi mahasiswa baik aspek makroskopik, mikroskopik, maupun simbolik pada fenomena kimia. Representasi makroskopik merupakan representasi kimia yang didapat dari pengamatan nyata dapat dilihat. Hasil pengamatan dapat direpresentasikan ke dalam bentuk laporan tertulis, diskusi, grafik, dan sebagainya. Representasi mikroskopik menjelaskan struktur dan proses pada level partikel terhadap fenomena makroskopik dan representasi simbolik dalam bentuk rumus kimia, diagram, gambar, persamaan reaksi, dan perhitungan matematik (Johnstone, 2006).

Penggunaan multipel representasi dalam pembelajaran bertujuan agar mahasiswa dapat memahami masalah dan memecahkan masalah (Scherr \& Stetzer, 2016). Multipel representasi juga memberikan peluang bagi mahasiswa untuk memahami dan mengkomunikasikan konsep (Fredlund et al., 2015). Kemampuan menghubungkan informasi yang ada pada ketiga representasi harus dimiliki oleh mahasiswa. Kemampuan ini perlu terus-menerus dilatih selama proses pembelajaran. Oleh karena itu, mahasiswa sebagai calon pendidik harus membiasakan menggunakan kemampuan multipel representasi dalam proses pembelajaran dan evaluasi pembelajaran dengan menyusun soal-soal yang memuat multipel representasi. Kemampuan pendidik dalam menyusun soal yang memuat multipel representasi sangat diperlukan agar dapat melaksanakan evaluasi pembelajaran secara terstruktur.

\section{METODE}

Penelitian ini menggunakan prosedur pengembangan Borg \& Gall yang telah dimodifikasi yaitu dibatasi hanya sampai pada tahap 7. Tujuh tahap tersebut yaitu 1) research and collect the data, 2) planning step, 3) development of early product step, 4) limited try out, 5) revision of early product, 6) field try out, dan 7) revision final product. Subjek penelitian adalah 27 mahasiswa pendidikan kimia yang menempuh mata kuliah Kimia Dasar 1 pada tahun ajaran 2019/2020.

Materi yang digunakan adalah struktur atom dengan 3 kali pertemuan. Pengenalan mengenai soal HOTS dan multipel representasi kepada mahasiswa diberikan pada pertemuan pertama, penyusunan soal HOTS pada pertemuan kedua, dan pembahasan soal HOTS pada pertemuan ketiga. Data penelitian berupa lembar angket, uji coba soal HOTS yang telah disusun oleh mahasiswa, dan wawancara. Wawancara dilakukan untuk mengetahui pemahaman mahasiswa mengenai materi struktur atom, 
pemahaman mahasiswa mengenai soal HOTS, dan kesulitan yang dialami saat membuat soal HOTS. Pedoman wawancara telah divalidasi oleh 3 orang dosen sebagai validator dan diperoleh hasil bahwa pedoman wawancara layak digunakan.

Data soal dianalisis dan dikelompokkan sesuai tingkatan proses kognitif taksonomi Bloom dan dihitung persentasenya. Hasil analisis berupa soalsoal yang termasuk kategori soal HOTS yaitu level C4, C5, dan C6 kemudian diuji coba. Hasil uji coba soal dianalisis lebih lanjut untuk mengetahui validitas, tingkat kesukaran, daya beda, dan reliabilitasnya. Data hasil wawancara dianalisis menggunakan analisis kualitatif deskriptif.

\section{HASIL DAN PEMBAHASAN}

Tahap pertama research and collect the data dari penelitian pengembangan ini adalah berangkat dari adanya permasalahan yang diperoleh berdasarkan hasil wawancara awal terhadap mahasiswa yang mengikuti mata kuliah Kimia Dasar 1

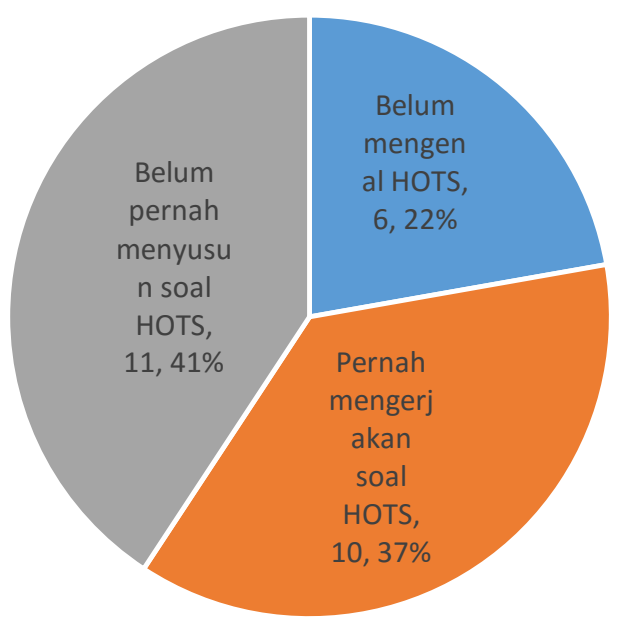

, 2020; accepted Feb 1, 2021 / Under licenced: CC-BY-SA diperoleh informasi bahwa sebanyak 6 mahasiswa belum mengetahui tentang soal HOTS. Sebanyak 21 mahasiswa sudah pernah mendengar tentang soal HOTS dengan rincian 10 mahasiswa sudah pernah mengerjakan soal HOTS dan 11 mahasiswa belum pernah mengerjakan maupun menyusun soal HOTS. Hal ini dikarenakan keberagaman asal daerah mahasiswa. Mahasiswa yang saat sekolah di Sekolah Menengah Atas di daerah perkotaan rata-rata telah dikenalkan dengan soal HOTS oleh guru.

Tahap dua planning step yaitu 1) menyusun indikator penilaian intrumen soal HOTS dan pedoman wawancara, 2) menentukan validitas pedoman wawancara, 3) melakukan pengembangan awal produk ang dimulai dengan pengenalan dan pelatihan soal HOTS dengan multipel representasi, 4) melakukan uji coba terbatas pada soal HOTS yang telah dikembangkan oleh mahasiswa, 5) melakukan revisi produk awal soal HOTS, 6) melakukan uji coba soal HOTS hasil revisi, dan 7) melakukan revisi terhadap soal HOTS hasil dari uji coba akhir. Tahap tiga development of early product diawali dengan mengenalkan pada mahasiswa dengan soal HOTS dan mutipel representasi dan berlatih menyusun soal kimia HOTS pada pertemuan pertama pembelajaran. Soal HOTS yang disusun

Gambar 1. Data Wawancara Awal 
difokuskan pada soal berbentuk multiplechoice atau pilihan ganda, walaupun bentuk soal evaluasi HOTS dapat dilakukan dengan cara lain yaitu menggeneralisasi (jawaban singkat, esai) dan memberi alasan (Iskandar \& Senam, 2015).

Mahasiswa mencoba membuat soal HOTS berbasis multipel representasi pada pertemuan kedua. Setiap mahasiswa membuat tiga soal masing-masing level $\mathrm{C} 4$, C5, dan C6. Pada awalnya mahasiswa merasa kesulitan dalam membuat kisi-kisi soal, tetapi dengan bantuan teman dan konsultasi dengan dosen pada akhirnya mereka dapat membuat kisi-kisi soal dan melanjutkan dengan menyusun soal HOTS. Mahasiswa yang menguasai materi lebih terlihat mampu menyusun soal HOTS dibandingkan dengan mahasiswa yang kurang menguasai materi. Hal ini dikarenakan mahasiswa dituntut menguasai materi, keterampilan dalam mengkonstruksi soal, dan kreatif dalam memilih stimulus agar dapat menyusun soal HOTS (Muliawati, 2020).

Karakteristik soal HOTS yang membedakan dengan soal bukan HOTS yaitu fokus pada pemecahan masalah, kemampuan berpikir kreatif dan kritis, kemampuan berargumen, dan kemampuan mengambil keputusan. Langkah-langkah penyusunan soal HOTS yaitu (1) melakukan analisis terhadap kompetensi dasar, (2) membuat kisi-kisi soal, (3) menggunakan stimulus supaya melatih keterampilan berpikir tingkat tinggi, (4) menyusun butir soal, dan (5) membuat pedoman penskoran (Fanani, 2018). Tabel 1 menunjukkan contoh kisi-kisi soal yang dibuat oleh mahasiswa. Kisi-kisi soal tersebut termasuk level kognitif C4 yaitu analisis. Soal ini menguji kemampuan analisis yaitu kemampuan untuk mengidentifikasi dan memisahkan komponen-komponen suatu fakta, konsep, pendapat, asumsi, hipotesa atau kesimpulan dan memeriksa ada atau tidaknya kontradiksi pada komponenkomponen tersebut (Hanik, 2020). Soal ini mengandung level simbolik berupa grafik tingkat energi pengisian elektron pada beberapa unsur. Siswa harus mampu menganalisis unsur-unsur tersebut sehingga mampu menentukan pasangan unsur yang terdapat dalam periode yang sama.

Kisi-kisi soal kedua level kognitif C5 yaitu evaluasi. Soal ini menguji kemampuan untuk membuat penilaian berdasarkan relevansi dimana di dalam soal diberikan tabel periodik unsur yang masih kosong. Soal ini memiliki aspek simbolik berupa gambar dan juga simbol unsur. Siswa harus mampu menggunakan kemampuan berpikir tingkat tinggi untuk dapat menentukan konfigurasi unsur yang 
benar dari unsur yang terdapat dalam tabel dimana siswa juga harus mampu menghubungkan dengan informasi mengenai sifat-sifat unsur yang terdapat dalam soal. Kisi-kisi soal ketiga yaitu level kognitif $\mathrm{C} 6$ yaitu mencipta. Soal ini menguji kemampuan siswa untuk merencanakan langkah-langkah yang benar dan urut dari langkah-langkah yang diberikan dalam soal. Representasi mikroskopik muncul dalam soal ini yaitu berupa partikel-partikel penyusun atom dan representasi simbolik berupa simbol atom.

Validasi terhadap soal dilakukan untuk menghasilkan soal yang baik dan dapat mengukur kemampuan siswa. Berdasarkan penilaian validasi oleh dosen diperoleh soal yang telah disusun oleh mahasiswa berjumlah 40 soal HOTS dengan target 81 soal jika masing-masing mahasiswa membuat tiga soal yaitu level C4, C5, dan C6 seperti ditunjukkan pada Tabel 2. Hal ini berarti hanya $49,4 \%$ target soal yang dapat terpenuhi. Sebanyak 41 soal yang lain tidak digunakan karena berdasarkan hasil validasi soal-soal tersebut tidak termasuk ke dalam HOTS, melainkan termasuk soal kategori LOTS. Soal-soal tersebut juga tidak memunculkan representasi makroskopik, mikroskopik, maupun simbolik. Selain itu, setelah diteliti beberapa soal diambil oleh mahasiswa dari internet sehingga tidak digunakan.

Berdasarkan hasil wawancara diperoleh bahwa sebanyak 17 mahasiswa kesulitan dalam menghubungkan informasi yang ada pada setiap representasi (interkoneksi). Mahasiswa yang memiliki kemampuan awal yang tinggi dan menguasai materi terlihat lebih mampu untuk melakukan interkoneksi pada setiap representasi (Cook et al., 2008). Hal ini juga berpengaruh pada kualitas soal yang disusun. Mahasiswa yang menguasai materi dengan baik terlihat lebih mudah dalam berpikir untuk membuat stimulus dalam soal HOTS dan mampu mengeksplorasi informasi dari berbagai sumber seperti buku, e-book, penjelasan dosen, maupun dari internet. Mereka tidak sekedar mengambil mentah-mentah soal HOTS dari internet. Stimulus yang dihasilkan juga mengandung representasi kimia.

Tahap empat limited try out yaitu dilakukan uji coba terbatas terhadap 40 soal tersebut dan diperoleh hasil seperti ditunjukkan pada Tabel 3. Dua soal tidak valid sehingga tidak digunakan dan dan tiga soal dengan daya beda jelek juga tidak digunakan. Total Sebanyak 11 soal layak digunakan dan reliabilitas soal sebesar 0,78 . 
Tabel 1. Contoh Kisi-Kisi Soal

\begin{tabular}{|c|c|c|c|}
\hline $\begin{array}{c}\text { Dimensi Proses } \\
\text { Kognitif }\end{array}$ & $\begin{array}{c}\text { Sub Dimensi } \\
\text { Proses Kognitif }\end{array}$ & Deskripsi & Soal \\
\hline $\mathrm{C4}$ & Menguraikan & $\begin{array}{l}\text { Menyimpulkan hasil } \\
\text { analisis dari bagian- } \\
\text { bagian pernyataan pada } \\
\text { stimulus berdasarkan } \\
\text { karakteristik yang } \\
\text { diinginkan }\end{array}$ & $\begin{array}{l}\text { Diberikan grafik tingkat energi } \\
\text { pada pengisian elektron empat } \\
\text { atom } A, B, C, D \text {, dan } E \text {. Siswa } \\
\text { diminta untuk menentukan } \\
\text { pasangan atom yang berada } \\
\text { pada periode yang sama dalam } \\
\text { sistem periodik unsur. }\end{array}$ \\
\hline $\mathrm{C5}$ & Memeriksa & $\begin{array}{l}\text { Membuat penilaian } \\
\text { sesuai dengan relevensi }\end{array}$ & $\begin{array}{l}\text { Diberikan tabel periodik unsur } \\
\text { kosong. Siswa diminta } \\
\text { menentukan konfigurasi } \\
\text { electron yang benar dari unsur } \\
\text { yang ditandai dalam tabel. }\end{array}$ \\
\hline C6 & Merencanakan & $\begin{array}{l}\text { Membuat rincian } \\
\text { langkah-langkah }\end{array}$ & $\begin{array}{l}\text { Diberikan langkah-langkah yang } \\
\text { belum urut mengenai } \\
\text { penentuan isotop, isobar, dan } \\
\text { isoton. Siswa diminta } \\
\text { menentukan langkah-langkah } \\
\text { yang urut untuk menentukan } \\
\text { pasangan yang merupakan } \\
\text { isotop. }\end{array}$ \\
\hline
\end{tabular}

Tabel 2. Hasil Penyusunan Soal HOTS

\begin{tabular}{ccccccc}
\hline & \multicolumn{7}{c}{ Kategori } & & & \\
& C1 & C2 & C3 & C4 & C5 & C6 \\
\hline Jumlah Soal & 12 & 7 & 6 & 9 & 4 & 2 \\
Persentase & $30 \%$ & $17,5 \%$ & $15 \%$ & $22,5 \%$ & $10 \%$ & $5 \%$ \\
\hline
\end{tabular}

Tahap lima yaitu revision of early product dilakukan pada pertemuan ketiga dengan membahas tentang soal HOTS yang telah disusun dengan diskusi kelas. Revisi dilakukan terhadap soal dalam hal redaksi kalimat dan pilihan jawaban yang kurang sesuai. Berdasarkan hasil wawancara didapatkan bahwa kesulitan mahasiswa dalam menyusun soal HOTS terletak pada aspek makroskopik materi struktur atom yang tidak dapat terlihat, kecuali sebatas analogi misalnya model atom Thomson yang dianalogikan seperti roti kismis.
Mahasiswa mengalami kesulitan dalam menghubungkan ketiga representasi kimia dalam materi struktur atom terutama mahasiswa yang belum pernah mengenal soal HOTS. Hal ini terlihat pada soal yang tidak memunculkan ketiga aspek tersebut dalam soal. Oleh karena itu, mahasiswa yang belum pernah mengenal soal HOTS sebaiknya memulai membuat soal dengan representasi simbolik dimana representasi ini tidak menyebabkan beban berlebih terhadap kapasitas kerja otak mahasiswa (Corradi et al., 2012). 
Tabel 3. Hasil Analisis Butir Soal HOTS

\begin{tabular}{cccccc}
\hline Butir & Kategori & Validitas & Tingkat Kesukaran & Daya Beda & Keputusan \\
\hline 1 & C4 & Valid & Sedang & Cukup & Diterima \\
2 & C4 & Tidak valid & Sedang & Cukup & Ditolak \\
3 & C4 & Valid & Sedang & Baik sekali & Diterima \\
4 & C4 & Valid & Sedang & Baik & Diterima \\
5 & C4 & Valid & Sedang & Baik & Diterima \\
6 & C4 & Valid & Sedang & Baik & Diterima \\
7 & C4 & Valid & Mudah & Baik & Diterima \\
8 & C6 & Valid & Sedang & Cukup & Diterima \\
9 & C5 & Valid & Sedang & Jelek & Ditolak \\
10 & C5 & Tidak valid & Sedang & Jelek & Ditolak \\
11 & C4 & Valid & Sedang & Cukup & Diterima \\
12 & C6 & Valid & Sedang & Jelek & Ditolak \\
13 & C4 & Valid & Sedang & Baik & Diterima \\
14 & C5 & Valid & Sedang & Cukup & Diterima \\
15 & C5 & Valid & Sedang & Cukup & Diterima \\
& & Reliabilitas & & 0,78 & \\
\hline
\end{tabular}

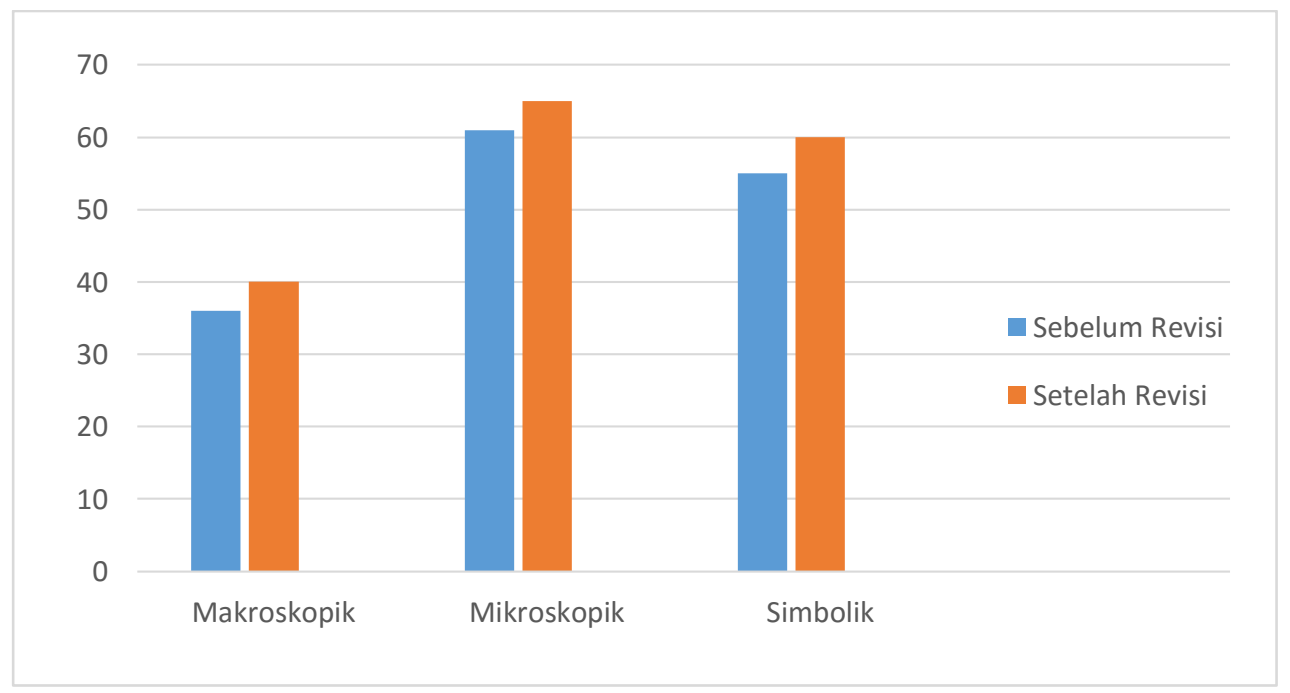

Gambar 2. Profil Aspek Multipel Representasi Pada Soal HOTS

Tahap enam yaitu field try out dimana sebanyak 11 soal HOTS yang telah direvisi diujicoba lapangan pada 90 siswa. Hasil uji coba ini untuk melihat apakah soal HOTS yang telah dikembangkan dapat dijadikan sebagai penilaian pembelajaran bagi siswa ditinjau dari aspek makroskopik, mikroskopik, dan simbolik. Berdasarkan hasil angket diperoleh bahwa masingmasing aspek representasi yaitu makroskopik sejumlah 36 siswa mengatakan baik, aspek mikroskopik sejumlah 61 siswa mengatakan baik, dan aspek simbolik sejumlah 55 siswa 
mengatakan baik. Hasil wawancara diperoleh bahwa aspek makroskopik dalam soal kurang jelas karena siswa kesulitan untuk memperoleh gambaran yang jelas tentang bentuk atom karena bentuknya yang tidak nyata, sedangkan dari aspek mikroskopik dan simbolik sudah jelas.

Tahap tujuh yaitu revision final product dilakukan agar ketiga aspek multipel representasi dalam soal HOTS yang dikembangkan dapat meningkat. Hal ini dilakukan dengan diskusi dimana mahasiswa yang merasa masih kesulitan dalam memahami soal HOTS dan multipel representasi mencoba kembali merevisi soal yang disusun dengan konsultasi dengan dosen maupun berdiskusi diantara mahasiswa. Mahasiswa perlu diberi latihan untuk menginterpretasikan struktur submikoroskopik dari suatu atom. Pengetahuan awal yang diperoleh mahasiswa saat masih di sekolah menengah belum mampu mengurangi kesulitan mahasiswa dalam mentransformasikan fenomena verbal ke visual. Kesulitan tersebut disebabkan kurangnya imajinasi yang baik dalam melakukan representasi mikroskopik tentang struktur atom dan adanya kesalahan pemahaman dalam menggambarkan model atom (Sunyono. et al., 2014). Berdasarkan hasil angket diperoleh peningkatan pada aspek makroskopik, mikroskpik, dan simbolik berturut-turut 40, 65, dan 60 siswa mengatakan baik seperti ditunjukkan Gambar 2.

Berdasarkan hasil wawancara terhadap mahasiswa terdapat kendalakendala yang dihadapi dalam menyusun soal HOTS materi struktur atom yaitu kesulitan dalam menerjemahkan aspek makroskopik karena struktur atom yang tidak nyata terlihat oleh mata dan kesulitan dalam membedakan level berpikir tingkat tinggi. Kesulitan ini dikarenakan mahasiswa belum dilatih dalam belajar dengan ketiga representasi kimia tersebut. Kendala tersebut diatasi dengan cara menstimulus mahasiswa untuk membayangkan yang ada di dalam atom dan strukturnya melalui gambar visual yang disediakan. Gambaran visual tersebut membuat mahasiswa melakukan interpretasi yang lebih baik dari sebelumnya dan membuat mereka lebih kreatif (Bland, 2012). Level makroskopik dalam pembelajaran materi struktur atom dapat dimunculkan dengan memperlihatkan fenomena dengan simulasi laboratorium yang kemudian diinterkoneksikan dengan level mikroskopik melalui animasi dan simulasi menggunakan komputer. Kedua level tersebut selanjutnya diinterkoneksikan dengan level simbolik melalui persamaan dan rumus kimia. Strategi tersebut dapat 
membantu mahasiswa untuk mengaplikasika ketiga representasi kimia ke dalam pemecahan masalah misalnya dalam menyusun soal HOTS (Sunyono et al., 2013).

\section{SIMPULAN}

Berdasarkan hasil dan pembahasan yang telah disebutkan di atas dapat disimpulkan bahwa telah dilakukan pengembangan soal HOTS menggunakan multipel representasi materi struktur atom dengan level C4 (analisis), C5 (evaluasi), dan C6 (mencipta) sebanyak 11 butir soal. Kemampuan multipel representasi mahasiswa pendidikan kimia dalam menyusun soal HOTS meningkat dilihat dari hasil angket yang menyatakan peningkatan pada aspek makroskopik, mikroskoipik, dan simbolik yang terdapat dalam soal HOTS sebelum dan sesudah revisi. Mahasiswa pendidikan kimia sebagai calon guru kimia perlu terus berlatih menyusun soal HOTS dan meningkatkan kemampuan multipel representasi pada materi kimia agar dapat membuat instrumen evaluasi HOTS berbasis multipel representasi.

\section{DAFTAR REFERENSI}

Afriyanti, I., Wardono, \& Kartono. (2018). Pengembangan Literasi Matematika Mengacu PISA Melalui Pembelajaran Abad Ke-21 Berbasis Teknologi. PRISMA, Prosiding Seminar Nasional Matematika, 1, 608-617.

Bland, D. (2012). Analysing children's drawings:
Applied imagination. International Journal of Research and Method in Education, 35(3), 235-242. https://doi.org/10.1080/1743727X.2012. 717432

Cook, M., Wiebe, E. N., \& Carter, G. (2008). The influence of prior knowledge on viewing and interpreting graphics with macroscopic and molecular representations. Science Education, 92(5), 848-867.

https://doi.org/10.1002/sce.20262

Corradi, D., Elen, J., \& Clarebout, G. (2012). Understanding and Enhancing the Use of Multiple External Representations in Chemistry Education. Journal of Science Education and Technology, 21(6), 780795. https://doi.org/10.1007/s10956012-9366-z

Fanani, M. Z. (2018). Strategi Pengembangan Soal Hots Pada Kurikulum 2013. Edudeena, 2(1), 57-76. https://doi.org/10.30762/ed.v2i1.582

Fredlund, T., Airey, J., \& Linder, C. (2015). Enhancing the possibilities for learning: Variation of disciplinary-relevant aspects in physics representations. European Journal of Physics, 36(5), 55001. https://doi.org/10.1088/01430807/36/5/055001

Hanik, N. R. (2020). Implementasi Model Pembelajaran Komparasi yang Diintegrasikan dengan Pendekatan Kolaboratif Ditinjau dari Kemampuan Analisis Mahasiswa Implementation of a Comparative Learning Model which is Integrated with a Collaborative Approach in terms of Student' s. Jurnal Komunikasi Pendidikan, 4(2), 114-122.

Heong, Y. M., Othman, W. B., Yunos, J. B. M., Kiong, T. T., Hassan, R. Bin, \& Mohamad, M. M. B. (2011). The Level of Marzano Higher Order Thinking Skillsamong Technical Education Students. International Journal of Social Science and Humanity, 1(2), 121-125. https://doi.org/10.7763/ijssh.2011.v1.20

Iskandar, D., \& Senam, S. (2015). Studi Kemampuan Guru Kimia Sma Lulusan Uny Dalam Mengembangkan Soal Uas Berbasis Hots. Jurnal Inovasi Pendidikan IPA, 1(1), 65. https://doi.org/10.21831/jipi.v1i1.4533 Johnstone, A. H. (2006). Chemical education research in Glasgow in perspective. 
Chemistry Education Research and Practice, 7(2), 49-63. https://doi.org/10.1039/B5RP90021B

Khaldun, I., Hanum, L., \& Utami, S. D. (2019). Pengembangan Soal Kimia Higher Order Thinking Skills Berbasis Komputer Dengan Wondershare Quiz Creator Materi Hidrolisis Garam Dan Larutan Penyangga. Jurnal Pendidikan Sains Indonesia (Indonesian Journal of Science Education), 7(2), 132-142. https://doi.org/10.24815/jpsi.v7i2.14702

Kusuma, M. D., Rosidin, U., Abdurrahman, A., \& Suyatna, A. (2017). The Development of Higher Order Thinking Skill (Hots) Instrument Assessment In Physics Study. IOSR Journal of Research \& Method in Education (IOSRJRME), 07(01), 26-32. https://doi.org/10.9790/73880701052632

Limbach, B., \& Waugh, W. (2010). Developing higher level thinking. Journal of Instructional Pedagogies, 9. https://aabri.com/manuscripts/09423.pd $\mathrm{f}$

Muliawati. (2020). Kemampuan Guru Dalam Menyusun Soal Berfikir Tingkat Tinggi Mata Pelajaran PPKN Pada UPT Satuan Pendidikan. Phinisi Integration Review, 3(1), 30-45.

Redhana, I. W. (2019). Mengembangkan Keterampilan Abad Ke-21 Dalam Pembelajaran Kimia. Jurnal Inovasi Pendidikan Kimia, 13(1).

Scherr, R. E., \& Stetzer, M. R. (2016). Editorial: Focused Collection: Preparing and Supporting University Physics Educators.
Physical Review Physics Education Research, 12(1), 10-13. https://doi.org/10.1103/PhysRevPhysEdu cRes.12.010002

Sunyono., Yuanita., L., \& Muslimin, I. (2014). Model Mental Mahasiwa Baru Dalam Memahami Konsep Struktur Atom Ditinjau Dari. 3(2), 346-353.

Sunyono, Yuanita, L., \& Ibrahim, M. (2013). Stoikiometri Sebelum Dan Sesudah Pembelajaran. Seminar Nasional Pendidikan Sains PPs, 499-509.

Voogt, J., \& Pareja Roblin, N. (2010). 21st Century Skills Discussion Paper - Voogt \& Pareja Roblin (2010).

Widana, I. W. (2017). Higher Order Thinking Skills Assessment (Hots). Jisae: Journal of Indonesian Student Assesment and Evaluation, 3(1), 32-44. https://doi.org/10.21009/jisae.031.04

Widarti, H., Sigit, D., \& Irianti, D. (2020). Pengaruh kemampuan awal terhadap kemampuan interkoneksi multi representasi siswa pada materi larutan penyangga. J-PEK (Jurnal Pembelajaran Kimia), 5(1), 40-46. https://doi.org/10.17977/um026v5i1202 0p040

Yusuf, I., \& Widyaningsih, S. W. (2018). Profil Kemampuan Mahasiswa Dalam Menyelesaikan Soal Hots Di Jurusan Pendidikan Fisika Universitas Papua. Jurnal Komunikasi Pendidikan, 2(1), 42. https://doi.org/10.32585/jkp.v2i1.63 